\title{
In vitro anthelmintic potential and phytochemical composition of ethanolic and aqueous crude extracts of Zanthoxylum chalybeum Engl.
}

\author{
A. S. Nalule ${ }^{1 *}$, J. M. Mbaria ${ }^{2}$ and J. W. Kimenju ${ }^{3}$ \\ ${ }^{1}$ Department of Wildlife and Aquatic Animal Resource, School of Veterinary Medicine and Animal Resources, Makerere \\ University, P.O. Box 7062 Kampala, Uganda. \\ ${ }^{2}$ Department of Public Health, Pharmacology and Toxicology, Faculty of Veterinary Medicine, University of Nairobi, P.O. \\ Box 29053-00625, Nairobi, Kenya. \\ ${ }^{3}$ Department of Plant Science and Crop Protection, Faculty of Agriculture, University of Nairobi, P. O. Box 2905300625 \\ Nairobi, Kenya.
}

Accepted 27 May, 2013

\begin{abstract}
Development of helminthes resistance to chemotherapeutic drugs coupled with high costs and misuse of conventional drugs call for the search of medicinal plants as alternative source of helminthes control. In vitro studies were conducted to determine the anthelmintic activity and phytochemical compounds of Zanthoxylum chalybeum. Bioassay was conducted using $70 \%$ ethanol and aqueous extracts' in serial dilutions parallel to serial dilutions of albendazole in three replicates. Ascaris suum model was used for the assays. Phytochemical methods and thin layer chromatography (TLC) were used for qualitative phytochemical analysis. The aqueous and ethanolic extracts of the $Z$. chalybeum inhibited 100 and $93 \%$ worm motility, respectively for $48 \mathrm{~h}$ post exposure. There was significant differences in motility inhibition by all dose levels' that were dose-dependent when compared with negative control $\left(F_{(5,53)}=10.62, P=0.001 ; R^{2}=0.92\right)$. There was a significant difference in mean motility inhibition by the different methods of extraction $\left(F_{(2,53)}=323.80, P=0.001\right)$. The $E D_{50}$ of ethanolic and aqueous extracts were 30.85 and $6.28 \mathrm{mg} / \mathrm{ml}$, respectively. The potency of the plants extracts and albendazole significantly differed $(P=0.001)$. The extracts contained tannins, saponins, flavonoids, alkaloids, reducing sugars, coumarins derivatives, anthracenones, and anthocyanins. TLC characterization indicated the presence of polyphenols and sapogenins. In conclusion, $Z$. chalybeum root extracts showed anthelmintic potential and the phytochemical compounds present justify the plant's ethno-veterinary use and could be used as improved traditional medicines.
\end{abstract}

Key words: Ascaris suum, medicinal plants, motility inhibition, Nakasongola.

\section{INTRODUCTION}

Helminthes infections remain a big challenge both in developed and developing countries despite being the most neglected among the healthcare systems. This is attributed to their chronic debilitating nature and the epidemiological characteristic of continuous contamination of the environment. In developing countries, the disease may be attributed to lack of resources to regularly de-worm affected individuals in addition to development of parasite resistance to conventional drugs resulting from poor use of drugs. Moreover, parasites infections are like to increase in the face of climate change (Weaver et al., 2010; Tinsley et al., 2011). It is 
well documented that parasites undergo evolution to adapt to opportunities presented by climate change or anthelmintic use or undoubtedly as a manifestation of 'survival of the fittest' (Sargison et al., 2007; Davey et al., 2009). The different control strategies including the use of anthelmintics, grazing management and improvements in sanitation, are available for gastrointestinal nematode infections, but these control methods are associated with many problems, such as development of resistance to the currently available chemotherapeutic anthelmintic drugs (Kaplan et al., 2004; Wolstenholme et al., 2004; Melaku et al., 2013). According to lan et al. (2007), it was concluded that "whether poor or rich livestock farmers, depending on their production systems and market conditions, the value of the animals in question may not warrant the cost of the professional veterinary care and inputs". Consequently, rural communities resort to using medicinal plants to treat symptomatic clinical signs of which they have continued to claim effectiveness. However, efficacies of the claimed potent plants have not been investigated to validate their traditional use as anthelmintics. One of these plants includes Zanthoxylum chalybeum Engl. (Nalule et al., 2011) called Chewing stick in West Africa.

$Z$. chalybeum commonly known as knob wood is a deciduous spiny shrub or tree up to $12 \mathrm{~m}$, often growing around termite mounds and in medium to low altitudes in dry woodland or grassland, with mean annual rainfall of 750 to $1500 \mathrm{~mm}$ (Dharani et al., 201). Z. chalybeum is commonly used by the pastoralists' communities in the semi arid Uganda commonly referred to as "cattle corridor" to treat a multitude of diseases of man and livestock. The root bark is used in treatment of internal parasites in livestock, treatment of odontitis, constipation, toothache and as mouth wash in humans while the leaves are used as beverage (Tran, 2011). Z. chalybeum is used to treat esophageal candidiasis and the root bark is powdered and added to tea (Runyoro et al., 2006). Recently, it was reported that in Kenya, the root bark concoction is used to treat malaria (Nguta et al., 2010). The fresh twigs of the plant from East Africa are used as toothbrush, air fresheners and for skin infections (Johns et al., 1990). In vitro anti-measles virus activity of the plant seed (Olila et al., 2002), antibacterial and antifungal activities (Olila et al., 2001a) as well as antiviral and trypanocidal (Olila et al., 2001b) have been reported.

In the cattle corridor, the root bark is used to treat internal parasites, while the leaves are used as beverage (Katende et al., 1995). In Tanzania, the fresh leaves of the plant are pounded with leaves of Acalypha fruticosa and Suregada zanzibariensis and the resulting juice is used to treat skin infections (Hedberg et al., 1983b). The fresh twigs of the plant from East Africa are used as toothbrush, air fresheners and for skin infections (Johns et al., 1990). In Kenya, antimicrobial activity of the root bark against Bacillus subtilis, Penicillium crustosum and Saccharomyces cerevisiae was reported (Taniguchi et al., 1978). In vitro anti-measles virus activity of the plant seed ethanol extract was demonstrated where the alkaloid skimmianine was reportedly responsible (Olila et al., 2002). Antibacterial and antifungal activities have been demonstrated (Olila et al., 2001a) as well as antiviral and trypanocidal (Olila et al., 2001b). Despite several reports on the traditional use of $Z$. chalybeum, little is known about the effectiveness or potential of $Z$. chalybeum as an anthelmintic plant. This study was therefore undertaken to determine the anthelmintic effectiveness of the ethanol and aqueous root back extracts on gastrointestinal nematodes using Ascaris suum model and to determine the $Z$. chalybeum qualitative phytochemical composition.

\section{MATERIALS AND METHODS}

\section{Collection of plant}

The root bark of $Z$. chalybeum was collected from the Ugandan cattle corridor in Nakasongola district based on the study conducted between January and March, 2010. Sample of the plant species used were collected and identified by a plant taxonomist at the Department of Botany Herbarium, Makerere University.

\section{Dosage adopted by community}

The amount of the plant parts used by the community was collected from five individuals. The fresh plant part amounts of each individual were weighed and the weights were recorded. The individual materials were oven dried at $60^{\circ} \mathrm{C}$ and thereafter reweighed and the mean recorded. The amount of the water used by the community for extracting active ingredient was considered and this was considered in dosage determination.

\section{Extraction of crude plant active ingredients and extraction efficiency determination}

Two hundred fifty grams $(250 \mathrm{~g})$ of dry plants material were macerated in $2000 \mathrm{ml}$ of $70 \%$ ethanol for $72 \mathrm{~h}$ with intermittent shaking in duplicates. Filtration through cotton wool was done to remove coarse particles (residues) and finely through filter paper (Whatman $\AA$, England). The filtrate was concentrated on Rota-vapor type Buchi-R, Switzerland under reduced pressure at $40^{\circ} \mathrm{C}$ and oven-dried at $50^{\circ} \mathrm{C}$. The mean yield of the duplicate samples were determined and recorded and thereafter packed into universal bottles and kept at $4^{\circ} \mathrm{C}$ till needed for bioassay tests.

Similarly, $250 \mathrm{~g}$ of fresh dried materials of the study plants were soaked in $2 \mathrm{~L}$ of distilled water with intermittent shaking for $72 \mathrm{~h}$. Thereafter, filtering was done to remove coarse material first with cotton wool and finely with Whatman filter paper $(12.5 \mathrm{~mm})$. The filtrate was concentrated under reduced pressure in a rotar evaporator as earlier mentioned. The concentrated filtrates were then evaporated to dryness in an oven at $50^{\circ} \mathrm{C}$ and yield was recorded. The water extracts were used shortly after drying to avoid spoilage since it was not freeze dried.

\section{Collection and maintenance of worms}

Adult worms were collected from small intestines of pigs obtained from the slaughter house in Kampala, Uganda. The adult worms were collected and transported in flask containing Goodwin's solution to the pharmacology laboratory, in the School of Veterinary 
Medicine and Animal Resources, Makerere University. In the laboratory, the active worms were washed in warm water at $37^{\circ} \mathrm{C}$ and placed in a clean flask where they were maintained in Goodwin's solution according to Lamson and Brown (1936) and Donahue et al. (1981) till the setting of the experiment.

\section{Preparation of Goodwin's physiological solution}

Goodwin's physiological solution was prepared from a number of chemical compounds including calcium chloride $(0.20 \mathrm{~g})$, glucose $(5.0 \mathrm{~g})$, magnesium chloride $(0.10 \mathrm{~g})$, potassium chloride $(0.20 \mathrm{~g})$, sodium bicarbonate $(0.15 \mathrm{~g})$, sodium chloride $(8.0 \mathrm{~g})$ and sodium hydrogen phosphate $(0.5 \mathrm{~g})$. All dissolved in $1000 \mathrm{ml}$ of distilled water. Calcium chloride was added later after dissolving others and glucose was added shortly and the resultant solution was prewarmed to $37^{\circ} \mathrm{C}$ before putting in the warms.

\section{Bioassay experimental design}

In preliminary experiments, the criteria used for assessing the effects of crude plant extracts on the motility of adult $A$. suum was developed and combined in the procedures described by Kotze et al. (2004), Paolini et al. (2004) and Marie-Magdeleine et al. (2009). Motility inhibition test using $A$. suum was selected due to its suitability for use in field or laboratory settings and ease of parasite identification as well as previous reports of its application to detect resistance to both the benzimidazole and macrocylic lactone drug groups (Gill et al., 1981).

Eighteen $250 \mathrm{ml}$ conical flasks were grouped into six groups with three replicates each. To each of the three flask of group one, 100 $\mathrm{ml}$ of Goodwin's solution was added to act as negative control. To groups 2 to 6 , serial dilutions of ethanolic crude plant extract ranging from 6.25 to $100 \mathrm{mg} / \mathrm{ml}$ for $Z$. chalybeum were added. In a parallel set up, 18 conical flasks were divided into six groups to cater for the negative control and the five level serial dilutions (concentrations from 6.25 to $100 \mathrm{mg} / \mathrm{ml}$ ) of positive control (Albendazole 10\%). At the end of the experiment, the procedure was repeated with serial dilutions of aqueous crude extract ranging from 4.5 to $72 \mathrm{mg} / \mathrm{ml}$. The lowest dose level represents half of the community dose based on extraction efficiency. Stock solutions were prepared by first dissolving weighed amount of the extract in 5 to $10 \mathrm{ml}$ of dimethyl sulfoxide (DMSO), then diluted by Goodwin's physiological solution to $600 \mathrm{ml}$ mark to make the highest concentration $(\mathrm{mg} / \mathrm{ml})$ with the same solution. Ten average size motile adult worms were randomly placed in each of the flask. The flasks and their contents were incubated at $37^{\circ} \mathrm{C}$ and checked for motility at 24 and $48 \mathrm{~h}$ during which all the parasites in each flask were assessed for paralysis, death or motility (active) and were recorded. A motility index was calculated as the ratio between the numbers of immobile worms/total number worms in the 3 flask per concentration.

\section{Phytochemical screening}

\section{Detection of specific phytochemical compounds}

The aqueous and ethanol extracts were qualitatively phytochemically analyzed using the standard methods described by Harbone (1973, 1998) and Tchamadeu et al. (2010) for the presence of alkaloids salts (Meyer's and Drangedorffs test), tannins (Styassny's reagent), saponins (foaming test), flavonoids (Shibata's reaction), reducing sugars (Fehling's tests), anthracenocides (Borntagen's reaction), coumarins (colour fluorescence under UV light), glycosides and triterpenoids (Liebermann-Burchard's test) and anthocynosides.
Separation of chemical groups by thin layer chromatography (TLC)

The separation of the various chemical groups was done on freshly prepared dry material plants extracts. A qualitative TLC analysis on silica gel was performed on of $Z$. chalybeum extracts in different migration systems according to Harborne (1973, 1998). Different detection agents were used with the purpose of characterizing the active principles responsible for biological effects or medicinal benefits. Vanillin-sulfuric acid reagent was employed for revealing terpenoid spots (triterpenes and saponins) while antimony trichloride was used for detection of development of blue-violet or brown spots indicative of polyphenol compounds (Wagner and Blatt, 1996). TLC analysis on silica gel was performed in chloroform/ methanol (9:1 v/v), EMW (100:17:13, v/v/v) and Xylene:MeOH (4:1, $\mathrm{v} / \mathrm{v})$ with antimony trichloride in concentrated $\mathrm{HCL}$ and vanillin sulphuric acid sprays for detection. Chromatograms were visualized in visible light and by ultra violet (UV) irradiation (254 nm). Preparatory chromatographic glass plates were prepared by dissolving $100 \mathrm{~g}$ of absorbent silica gel, in $250 \mathrm{ml}$ of distilled water $(1: 2.5)$ which was spread on glass plates and left in situ to dry overnight followed by activation by heating in the oven at $120^{\circ} \mathrm{C}$ for $40 \mathrm{~min}$.

To a stationary phase (silica gel), extract drops were put on a mark and immersed in a preferred solvent system to wait for 40 min of mobile phase movement followed by drying and visualization under visible light and UV irradiation $(254 \mathrm{~nm})$ during which the relative fractions $\left(R_{\mathrm{fs}}\right)$ of fluorescent spots were recorded. Thereafter, the plates were sprayed with antimony trichloride (phenolics compounds) and vanillin agents and heated at $120^{\circ} \mathrm{C}$ for $10 \mathrm{~min}$ after spraying with the reagents following standard procedures (Ciulei, 1964; Harborne, 1973; Wagner and Blatt, 1996) and the spot colors and distances moved were recorded against stationary phase.

\section{Data analysis and determination of $\mathrm{ED}_{50}$ of the extracts}

The bioassay data was analyzed by the Generalized Linear Model procedures for regression, $E_{50}$ determination. Graph Pad Prism version 5.01 software (Inc San Diego, CA USA) and GenStat Release 13.2 (PC/Windows7) softwares were also used to determine the means of percent motility inhibition, regression equations $\left(\mathrm{Y}_{(1,2,3)}=\mathrm{A}_{(1,2,3)}+\mathrm{C}_{(1,2,3)} /\left(1+\operatorname{EXP}\left(-\mathrm{B}_{(1,2,3)} \times\left(\mathrm{X}-\mathrm{M}_{(1,2,3)}\right)\right)\right)\right)$ and $95 \%$ confidence intervals $(\mathrm{Cl})$ and to generate the doseresponse curves. Two-way analysis of mean variance was carried out in GenStat Release 13.2 followed by Bonferroni post hoc $t$-test and $p$ - value $=0.05$ was used for significance level.

\section{RESULTS}

\section{Community dosage and extraction efficiency of $Z$. chalybeum in water and $70 \%$ ethanol solvents}

The mean dry weight of root bark used by the community was established to be $165.70 \pm 11.88 \mathrm{~g}$ which was boiled in $2 \mathrm{~L}$ of water. The mean yields and extraction efficiency of $250 \mathrm{~g}$ of the plant dry material in ethanol and water solvents are shown in Table 1.

\section{In vitro anthelmintic activity of ethanolic and aqueous extracts of the selected plants}

The $48 \mathrm{~h}$ exposure of adult $A$. suum to both ethanolic and 
Table 1. Solvent extraction efficiency ( $\mathrm{g} / 250 \mathrm{~g}$ of dry root bark) of ethanolic and aqueous extracts of the crude plants' extracts.

\begin{tabular}{lcc}
\hline Variable & Ethanolic extract (Mean \pm SEM (g)) & Water extract (Mean \pm SEM $(\mathbf{g}))$ \\
\hline Community adopted dry weights used & NA & $165.70 \pm 11.88$ \\
Extract yield (Mean \pm SEM (g)) & $38.80 \pm 4.30^{\mathrm{b}}$ & $56.67 \pm 1.67^{\mathrm{a}}$ \\
Extraction efficiency (\%) & 15.6 & 22.7 \\
\hline
\end{tabular}

Comparison was done between the solvents used and values with different superscript in a row are statistically significant $(P=0.004)$.

Table 2. The dose-response effects of crude extracts of Zanthoxylum chalybeum on adult Ascaris suum motility $48 \mathrm{~h}$ post treatment.

\begin{tabular}{lccc}
\hline Treatment & $\begin{array}{c}\text { Dose } \\
(\mathbf{m g} / \mathbf{m l})^{\star}\end{array}$ & $\begin{array}{c}\text { Motility inhibition } \\
(\text { Mean } \pm \text { SEM }(\%))\end{array}$ & $\begin{array}{c}\text { 95\% confidence interval of } \\
\text { motility inhibition }\end{array}$ \\
\hline & 0.00 & $0.00 \pm 0.00^{\mathrm{a}}$ & $-11.27-11.27$ \\
Ethanolic extract & 6.25 & $16.67 \pm 3.33^{\mathrm{b}}$ & $5.40-27.93$ \\
& 12.50 & $33.33 \pm 3.33^{\mathrm{c}}$ & $22.07-44.60$ \\
& 25.0 & $56.67 \pm 8.82^{\mathrm{d}}$ & $45.40-67.93$ \\
& 50.0 & $83.33 \pm 3.33^{\mathrm{e}}$ & $72.07-94.60$ \\
& 100.0 & $93.33 \pm 5.77^{\dagger}$ & $82.07-104.60$ \\
& & & \\
Aqueous extract & 0.0 & $0.00 \pm 0.00^{\mathrm{a}}$ & $-11.27-11.27$ \\
& 4.5 & $26.67 \pm 3.33^{\mathrm{b}}$ & $15.40-37.97$ \\
& $9.0^{\text {cd }}$ & $63.33 \pm 6.67^{\mathrm{c}}$ & $52.07-74.60$ \\
& 18.0 & $66.67 \pm 3.33^{\mathrm{d}}$ & $55.40-77.93$ \\
& 36.0 & $86.67 \pm 3.33^{\mathrm{e}}$ & $75.40-97.93$ \\
& 72.0 & $100.00 \pm 0.00^{\dagger}$ & $88.73-111.27$ \\
& & & $-8.91-8.91$ \\
Albendazole & 0.00 & $0.00 \pm 0.00^{\mathrm{a}}$ & $17.76-42.24$ \\
& 6.25 & $30.00 \pm 10.0^{\mathrm{b}}$ & $34.43-58.91$ \\
& 12.50 & $46.67 \pm 12.20^{\mathrm{c}}$ & $64.43-88.91$ \\
& 25.00 & $76.67 \pm 8.82^{\mathrm{d}}$ & $77.76-102.24$ \\
& 50.00 & $90.00 \pm 5.77^{\mathrm{e}}$ & $87.76-112.24$ \\
\hline
\end{tabular}

*Three replicates per treatment dose; Number of worms used, $\mathrm{N}=10 ;{ }^{\mathrm{cd}}$ Dose adopted by community; Goodwin's solution used in negative control. Mean values in the same treatment with different superscript in a column are statistically significant $(\mathrm{P}<0.05)$.

aqueous extracts at different concentrations produced a comparable and dose-dependent reduction in motility and/or mortality to the negative and positive control groups (Table 2). A significant difference in all dose levels on motility inhibition that was dose-dependent irrespective of solvent used for extraction when compared with negative control was observed using generalized linear model; $Z$. chalybeum $\left(F_{(5,53)}=10.62\right.$, $\left.P=0.001 ; R^{2}=0.92\right)$. There was however, no significant variation $(P>0.05)$ in motility inhibition when the plant crude ethanolic and aqueous extracts were compared with the positive control, albendazole. Similarly, there was no significant interaction between methods of extraction and the dose effect on motility inhibition in $\left(F_{(10}\right.$,
53) $=1.69, P=0.125)$.

\section{Median effective dose $\left(E D_{50}\right)$ and anthelmintic potency of plant crude extracts}

Table 3 presents the median effective dose $\left(E_{50}\right)$ of the root bark extracts and positive control while Figure 1 demonstrates the potency of the plant extracts as compared to albendazole. The results showed that the aqueous extract was more potent than the albendazole and ethanolic extract demonstrated by the shift of the graph to the left. The median effective doses of $Z$. chalybeum extracts and albendazole significantly differed 
Table 3. The median effective doses $\left(E D_{50}\right)$ of the ethanol and water extracts and albendazole.

\begin{tabular}{lccc}
\hline Extract/treatment & Worm motility inhibition (\%) & Median effective dose $\left(\mathrm{ED}_{\mathbf{5 0}}\right)(\mathbf{m g} / \mathbf{m l})$ & $\mathbf{9 5 \%} \mathbf{C l}$ of $\mathrm{ED}_{\mathbf{5 0}}$ \\
\hline Ethanol & 93 & $30.85^{\mathrm{a}}$ & $15.73-60.50$ \\
Water & 100 & $6.28^{\mathrm{b}}$ & $3.79-10.41$ \\
Albendazole & 100 & $15.12^{\mathrm{b}}$ & $6.95-32.90$ \\
\hline
\end{tabular}

Comparison was done between the $\mathrm{ED}_{50}$ of solvents used and values with different superscript are statistically significant $(P<0.05)$.

Table 4. Phytochemical constituents of water and ethanol extracts of $Z$. chalybeum root bark.

\begin{tabular}{lcc}
\hline Tested compound & Aqueous extract & 70\% Ethanolic extract \\
\hline Tannins & ++ & ++ \\
Reducing sugars & + & ++ \\
Saponins & ++ & $\mathrm{x}$ \\
Alkalloid salts & ++ & ++ \\
Anthracenosides & ++ & ++ \\
Coumarin derivatives & ++ & ++ \\
Flavonosides & +++ & +++ \\
Steroid glycosides & ++ & ++ \\
Triterpenes & ++ & ++ \\
Anthocyanosides & ++ & ++ \\
\hline
\end{tabular}

$(+)$ weakly present, $(++)$ moderate, $(+++)$ strongly present, $(\mathrm{x})$ not tested in ethanol extract

$\left(F_{(2,53)}=323.80, P=0.001\right)$. Thus, medicinal plant extract potency varies with the method of bioactive ingredients extraction.

\section{Phytochemical constituents characterization of aqueous and ethanolic extracts of $Z$. chalybeum}

Table 4 presents the qualitative phytochemical compounds detected in ethanolic and aqueous extracts of $Z$. chalybeum root bark while compounds characterization by TLC is shown in Table 5.

\section{DISCUSSION}

The aim of this study was to determine the anthelmintic activity and phytochemical constituents of $Z$. chalybeum root bark utilized by the agro-pastoral communities in Ugandan cattle corridor. Indeed, researchers need to identify possible candidates for new drug development by pharmaceutical industries to address the drug resistance and emerging diseases.

The results of this study have shown the anthelmintic potential of the $Z$. chalybeum and support the claims by the Nakasongola agro-pastoral farmers and previous reports that this plant treats helminthes infections in livestock (Nalule et al., 2011). However, the study revealed a wide variation in the dosage adopted by the community which shows that different individual using the plants achieves different control benefits. The community probably uses that amount due to the fear that the plant may be toxic in higher doses. Continued administration of low doses of plant crude extract to parasites may lead to the risks of development of resistance from repeated low doses exposure.

The study also revealed that the solvent used in extraction of active ingredient affect the anthelmintic activity obtained. This may be attributed to the types of compounds that are extracted depending on polarity and solubility in different solvents, and their biological effects on parasites. Other studies made similar observations (Gakuya, 2001; Costa et al., 2008) where they used different solvents for extraction observed varying bioactivity results. The study revealed that both the aqueous and ethanol extracts of the root bark of $Z$. chalybeum, significantly inhibited $A$. suum motility in a dose-dependent response by paralyzing them or causing their death with varying efficacies when compared with albendazole demonstrating the anthelmintic potential of the medicinal plants in the Ugandan cattle corridor. The variation in efficacy may also be attributed to the method of extraction, which may have yielded specific compounds, source of parasites and previous exposure to the plants. Waterman (1992) reported that plant metabolites are unstable molecules and their biological activity are dependent on their structure, physical and chemical properties. It is therefore possible that the parasite paralysis and/or death observed may have been 
Table 5. Thin layer chromatography characterization of $Z$. chalybeum compounds under different solvent systems, sprays and observations regimes.

\begin{tabular}{|c|c|c|c|c|c|c|c|c|c|c|c|c|}
\hline \multicolumn{5}{|c|}{ Chloroform/Methanol $(9: 1, \mathrm{v} / \mathrm{v})$, solvent front 11.0} & \multicolumn{4}{|c|}{$\begin{array}{c}\text { Ethyl acetate/Methanol/Water } \\
(100: 17: 13, v / v / v) \text { solvent front } 10.0\end{array}$} & \multicolumn{4}{|c|}{$\begin{array}{c}\text { Xylene/Methanol }(4: 1, \mathrm{v} / \mathrm{v}) \text { solvent } \\
\text { front } 10.0\end{array}$} \\
\hline $\mathbf{R}_{\mathrm{f}} \mathbf{x} 100$ & $\begin{array}{l}\text { Visible } \\
\text { light }\end{array}$ & $\begin{array}{l}\text { UV } \\
\text { light }\end{array}$ & $\begin{array}{c}\text { Antimony } \\
\text { trichloride } \\
\text { spray }\end{array}$ & $\begin{array}{l}\text { Vanillin } \\
\text { spray }\end{array}$ & $\begin{array}{l}\text { Visible } \\
\text { light }\end{array}$ & $\begin{array}{l}\text { UV } \\
\text { light }\end{array}$ & $\begin{array}{c}\text { Antimony } \\
\text { trichloride } \\
\text { spray }\end{array}$ & $\begin{array}{l}\text { Vanillin } \\
\text { spray }\end{array}$ & $\begin{array}{l}\text { Visible } \\
\text { light }\end{array}$ & $\begin{array}{l}\text { UV } \\
\text { light }\end{array}$ & $\begin{array}{c}\text { Antimony } \\
\text { trichloride } \\
\text { spray }\end{array}$ & $\begin{array}{l}\text { Vanillin } \\
\text { spray }\end{array}$ \\
\hline 8.0 & $\mathrm{Y}$ & B & $\mathrm{Y}$ & $\mathrm{Y}$ & B & $B$ & - & - & - & $\mathrm{Y}$ & - & - \\
\hline 16.7 & - & 0 & Y & - & - & - & - & - & DY & & - & - \\
\hline 20.0 & - & - & - & - & - & - & - & - & - & $\mathrm{O}$ & - & $P$ \\
\hline 22.7 & Y & - & - & Y & - & - & - & - & - & & - & - \\
\hline 25.0 & - & LB & B & $P$ & $\mathrm{~B}$ & $\mathrm{~B}$ & Y & - & - & & - & - \\
\hline 35.4 & - & $\mathrm{O}$ & - & - & OY & OY & - & OY & Y & DB & - & - \\
\hline 43.7 & - & - & $\mathrm{BR}$ & - & - & - & - & - & - & & BR & - \\
\hline 44.0 & - & - & - & - & - & - & - & - & - & LB & - & - \\
\hline 50.0 & - & - & - & - & - & - & - & - & - & $\mathrm{BR}$ & - & - \\
\hline 53.1 & - & - & - & - & - & - & - & - & LY & & - & - \\
\hline 56.4 & - & - & - & - & B & B & - & - & - & & - & - \\
\hline 57.6 & - & - & - & - & - & - & - & BR & - & & - & $P$ \\
\hline 61.8 & - & - & - & - & - & - & - & - & - & & PK & - \\
\hline 62.9 & - & - & - & - & - & - & - & - & - & & - & $P$ \\
\hline 64.5 & - & - & - & - & - & - & - & - & - & B & - & - \\
\hline 75.5 & - & - & - & - & - & - & - & - & - & $\mathrm{O}$ & - & - \\
\hline 84.1 & - & - & - & - & - & - & - & - & LY & & - & - \\
\hline 86.5 & - & - & $P$ & - & - & - & PP & - & - & & Y & DB \\
\hline 87.1 & - & $Y$ & - & - & - & - & - & - & - & 0 & - & - \\
\hline 91.5 & - & - & PK & PK & - & - & - & - & - & & - & - \\
\hline 93.2 & - & B & - & - & B & - & - & - & - & & - & - \\
\hline 96.0 & - & - & GY & - & - & - & - & - & - & & - & - \\
\hline 97.3 & - & 0 & - & $\mathrm{BR}$ & 0 & - & - & $\mathrm{BR}$ & - & & - & - \\
\hline 98.5 & - & - & Y & G & - & - & - & - & - & & - & - \\
\hline Total spots & 2 & 6 & 8 & 6 & 6 & - & 2 & 3 & 4 & 8 & 7 & 4 \\
\hline
\end{tabular}

$Y=$ yellow; $G=$ green; $D G=$ dark green; $L Y=$ light yellow; $P=$ purple; $P K=$ pink; $D Y=$ deep yellow, $B=B l u e ; O=$ orange; $L B=L$ ight blue, $D R=d e$ ep red; $R=$ red; $B R=b r o w n ; D B=d a r k$ brown; $\mathrm{GY}=\mathrm{grey} ; \mathrm{V}=$ violet. Spots at same $\mathrm{R}_{\mathrm{f}}$ with similar colours are similar or related.

attributed to plant metabolites (Table 4) like tannins, alkaloids salts and saponins among others (Makut et al., 2008). This study identified the presence of tannins, saponins, alkaloid salts, anthracenosides, coumarin derivatives, flavonosides, steroid glycosides, triterpenes and anthocyanosides. However, other studies on $Z$. chalybeum had revealed the presence of other specific compounds. For instance, structure elucidation using nuclear magnetic resonance (NMR), EIMS and UV spectroscopy by Aluoch (2000) who reported the presence of the benzophenanthridine 


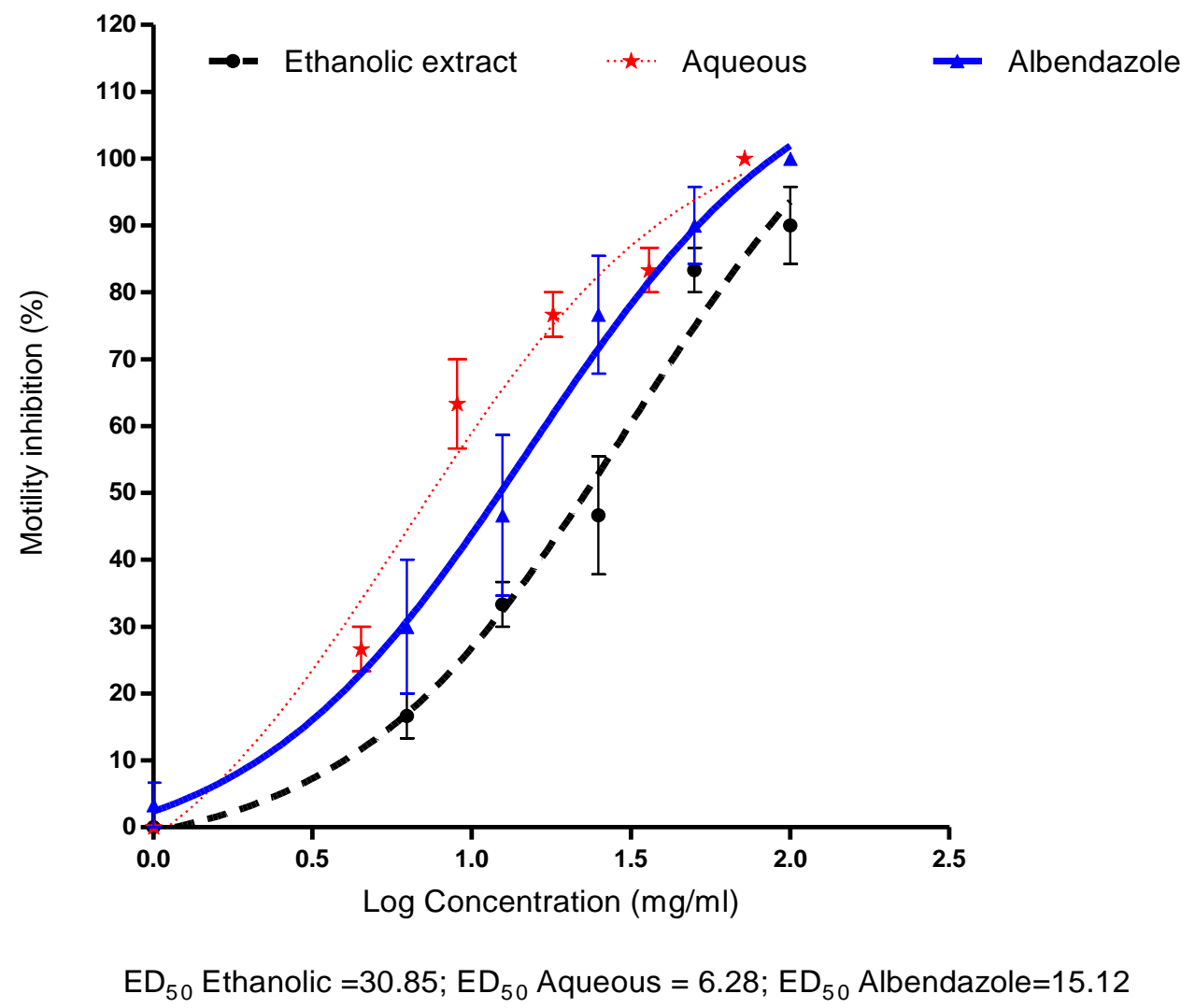

Figure 1. Dose-response curves of adult Ascaris suum motility inhibition by ethanol and water crude extracts of Zanthoxylum chalybeum and albendazole, $48 \mathrm{~h}$ post treatment. Nonlinear regression curves of treatments are defined as; $Y_{(1,2,3)}=A_{(1,2,3)}+C_{(1,2,3)} /\left(1+\operatorname{EXP}\left(-B_{(1,2,3)} \times(X-\right.\right.$ $\left.\left.M_{(1,2,3)}\right)\right)$ ). Where $Y_{(1,2,3)}$ are proportions of worm motility inhibited by ethanol, water extracts and albendazole. $A$ is $Y$-value when $X=0$; $C$ is the top - bottom of each curve, that is, $X=0$ and $X=$ maximum; $B$ is a rate constant expressed as reciprocal of $X ; M$ is random error and $X$ is the dose of treatment (ethanolic, aqueous and albendazole). $A_{1}, A_{2}, A_{3}$ and $C_{1}, C_{2}, C_{3}$ are parameter estimates for ethanolic and aqueous extracts and albendazole, respectively given as $0.03,-4.90,2.93$ with s.e of, $5.93,8.94,6.20$, respectively and $104.0,112.7,103.0$ with s.e of $16.0,21.3,13.2$ respectively. While, the constants $B_{1}, B_{2}, B_{3}=3.411,2.60,3.333$ with s.e of $0.982,0.979,0.946$ respectively and $M_{1} M_{2}, M_{3}=1.335,0.962,1.1672$ with s.e of $0.104,0.114$ and 0.0887 respectively. $X=$ treatment doses (level 1 to level 6 ) for each treatment). Percentage variance accounted for 92.3 and standard error of observations was estimated to be 9.87 . The error bars show the standard error of the percent worm motility inhibition.

alkaloids dihydrochelerythrine and chelerythrine, the 2,6diaryl-3,7-dioxabicyc10[3.3.0]octane lignans $(+)$ sesamin (3) and (-) asarinin (4), the quinolone alkaloid 4-methoxy$\mathrm{N}$-methyl-quinolin-2-one (5) and the triterpene. Different studies (Kato et al., 1996; Olila et al., 2002) have reported the presence of alkaloid skimmianine while another study on $Z$. chalybeum root and stem bark have reported the presence of polyphenols and their antiplasmodial and oxidant activity (Stangeland et al., 2010). It is therefore likely that these compounds could have anthelmintic activity that may have worked singly or in combination to cause the motility inhibition or paralysis of the worms that was achieved in all the studied crude extracts. Synergistic interactions have been suggested to underlie the effectiveness of phyto-medicines that lead to better activity as well as decrease potential toxicity of some individual constituents (Kaufman et al., 1999). It has also been reported that the plant metabolites action may be additive, synergistic or antagonistic in manner acting at single or at multiple target sites (Briskin, 2000; Wynn and Fougere, 2007).

Nevertheless, it is well documented that some anthelmintic drugs like the benzimidazoles (BZD) kill the parasites by binding to a specific building block, the beta tubulin and prevent its incorporation into micro-tubules which are essential for energy metabolism (Schoenian, 2008). The benzimidazole anthelmintics are said to act by interfering with the microtubule system in $A$. suum (Barrowman et al., 1984). Thus, these compounds could have caused their effect through the same mechanism. 
Paralysis of worm tissues makes them unable to feed leading to death as a result of lack of energy. It is also likely that alkaloids present in the plants could also have contributed to the paralysis and consequent death of the worms. The nematocidal activity of alkaloids had also been demonstrated when they used two rat nematodes; Strongyloides ratti and Strongyloides venezuelensis models for human nematodes (Satou et al., 2002). Alkaloids salts on the other hand are competitive antagonists at muscarinic acetylcholine receptor preventing the binding of acetylcholine and are reportedly physiologically active with sedative and analgesic properties in addition to leading to excitation of cells and neurological dysfunction (Tarnopolsky and Beal, 2001). On the other hand the saponins present in the crude extract could have caused feed refusal and starvation of the parasites leading to their death from lack of energy. Similar views on saponins effects of feeding were held by other authors who also reported that saponins kill protozoans and molluscs (Dalsgaard et al., 1990; Francis et al., 2002). It is also probable that in vivo paralysis lead to loss of grip of parasites on the gut wall leading to the spontaneous expulsion of parasites together with feaces.

The roles of tannins in helminths control have been documented (Athnasiadou et al., 2001a; Cenci et al., 2007; Forbey et al., 2009). The nematocidal activity of tannin extracts has also been reported with evidence of anthelmintic properties of condensed tannins by series of in vitro studies (Dawson et al., 1999; Athanasiadou et al., 2001a; Ademola and Idowu, 2006) and in vivo studies (Butter et al., 2001). Chemically, tannins are polyphenolic compounds (Bate-Smith, 1962) and synthetic phenolic anthelmintics like niclosamide and oxyclozanide are said to interfere with energy generation in helminths parasites by uncoupling oxidative phosphorylation (Martin, 1997). It is possible that tannins contained in ethanol and water extracts of $Z$. chalybeum produced similar effects. It was also suggested that tannins bind to free proteins in the gastrointestinal tract of the host animal (Athanasiadou et al., 2001b; Hoste et al., 2006) or glycoprotein on the cuticle of the parasite disturbing the physiological functions like motility, feed absorption and reproduction (Aerts et al., 1999; Githiori et al., 2006) or interference with morphology and proteolytic activity of microbes causing death (Min et al., 2003; Waghorn and McNabb, 2003). Alternatively, the presence of alkaloids salts which are physiologically active with sedative and analgesic properties could have contributed to the paralysis and consequent death of the worms. Alkaloids have been reported to be toxic resulting from their stimulatory effects that lead to excitation of cells and neurological dysfunction (Rujjanawate et al., 2003).

The study further established that the anthelmintic activity of the plant extracts varied among the increasing concentration and incubation period. Increasing effect with increasing concentration could be due to the fact that some chemical compounds slowly get released and their effect depends on saturation of target receptors. Similar observation were made by Lullman et al. (1993) who said that the receptors get saturated with increasing dose of active ingredient that increases with incubation period. It is likely that at higher concentration all binding receptors on the worms were occupied thus leading to hyperpolarisation of membranes limiting excitation and impulse transmission, thus causing flaccid paralysis of worm muscles (Wasswa and Olila, 2006).

The extract potency (Figure 1) may be a result of synergistic action of some compounds present in different extracts. Despite the many compounds present in extracts, it is likely only a few that could be important as anthelmintics. The great variation in potencies based on the $E D_{50 s}$ (Table 3), could be due to presence of difference in compound structure as some could have occur as an isomer or derivatives of the bigger molecules and their difference in concentration. Occurrence of several fluorescent spots in TLC at different relative fractions $\left(R_{\mathrm{fs}}\right)$ within a given system under same observation conditions may be suggestive of the presence of same compounds but different molecular mass, or isomers, or derivatives of a given class of compounds and probably the same chemical structure. The appearance of the pink/purple colour under vanillin spray may be suggestive of the presence of phenolic compounds while purple staining with antimony chloride probably indicate the presence of sapogenins in $\mathrm{CHCL}_{3}: \mathrm{MeOH}$ system according to Harbone (1984). TLC characterization results typically demonstrate these minor differences in structure thus concentration. Similar observations were made by Waterman et al. (2010). It is likely that the solvent used in extraction of active ingredients could be responsible for the crude extract potency. This is in support of the observations made by Malu et al. (2009).

The compound could also be having similar functional groups though not the same but with some relationship and absorbing at different wavelength. It is also probable that the richer the plant species in bioactive compounds the more effective and potent since the compounds work in isolation or in combinations to bring about biological effects in the animal through synergy and/or additive action to enhance the medicinal value of the group of compounds. The compounds present in the extract probably justify their use by the community for health benefits.

\section{CONCLUSION AND RECOMMENDATION}

This study results suggest that the root bark of $Z$. chalybeum have potential anthelmintic activity justifying their traditional ethno-veterinary use by the pastoral communities not withstanding under dosing revealed in the cattle corridor of Uganda that could be exploited for 
sustainable livestock helminths control or reduce the risk of helminths resistance to conventional drugs.

The study has also shown that the efficacy and potency of the plant extract depend upon the solvents used to extract the bioactive ingredient although ethanol and water solvents could be used interchangeably to take advantage of preservation of ethanol and economics of aqueous solvents.

The phytochemical constituents present in the plant validates the basis for their use as anthelmintic "drugs" and direct to plant's role in medicinal uses. However, the plant needs to be studied in vivo to establish the effect of digestive enzymes on efficacy in addition to determining toxicity in animals, bioavailability and bio-acceptability and safety of this noble plant species.

Over-harvesting of roots could lead to endangerment of this tree, should commercial exploitation break-even or routine used for preventive purposes on a flock-wide basis. Given that the $Z$. chalybeum roots are targeted by current users, it is warranted to assess the anthelmintic activity of leaves that would allow for less destructive harvesting to promote its conservation.

\section{REFERENCES}

Ademola IO, Idowu SO (2006). Anthelmintic activity of Leucaena leucocephala seed extract on Haemonchus contortus-infective larvae. The Veterinary Record 158:485-486

Aerts RJ, Barry TN, McNabb WC (1999). Polyphenols and agriculture: beneficial effects of proanthocyanidins in forages. Agric. Ecosyst. Environ. 75:1-12.

Aluoch AO (2000). Chemistry and biological activities of Zanthoxylum chalybeum and Erythrina excelsa. MSc thesis, University of Nairobi, Kenya.

Athanasiadou S, Kyriazakis I, Jackson F, Coop RL (2001b). The effects of condensed tannins supplementation of foods with different protein content on parasitism, food intake and performance of sheep infected with Trichostrongylus colubriformis. Brit. J. Nutr. 86:697-706.

Athanasiadou S, Kyriazakis I, Jackson F, Coop RL (2001a). Direct anthelmintic effects of condensed tannins towards different gastrointestinal nematodes of sheep: In vitro and in vivo studies. Vet. Parasitol. 99:205-219.

Barrowman MM, Marriner SE, Bogan JA (1984). The binding and subsequent inhibition of tubulin polymerization in Ascaris suum (in vitro) by benzimidazole anthelmintics. Biochem. Pharmacol. 33(19):3037-3040.

Bate-Smith EC (1962). The phenolic constituent of plants and their taxonomic significance, dicotyledons. J. Linn. Soc., Bot. 58:95-103.

Briskin DP (2000). Medicinal plants and phytomedicines: Linking plant Biochemistry and physiology to human health. Updates on phytomedicines. Plant physiol. 124:507-514.

Butter NL, Dawson JM, Wakelin D, Buttery PJ (2001). Effect of dietary condensed tannins on gastrointestinal nematodes. J. Agric. Sci. 137:461-469.

Cenci FB, Louvandini H, McManus CM, Dell'Porto A, Costa DM, Araújo SC, Minho AP, Abdalla AL (2007). Effects of condensed tannin from Acacia mearnsii on sheep infected naturally with gastrointestinal helminthes. Vet. Parasitol. 144:132-137.

Ciulei J (1964). Manual for analysis of vegetables drugs.

Costa CTC, Bevilaqua CML, Camurça-Vasconcelos ALF, Maciel MV, Morais SM, Castro CMS, Braga RR, Oliveira LMB (2008). In vitro ovicidal and larvicidal activity of Azadirachta indica extracts on Haemonchus contortus. Small Ruminant Res. 74(1-3):284-287.

Dalsgaard K, Hilgers L, Trouve G (1990). Classical and new approaches to adjuvant use in domestic food animals. Adv. Vet. Sci. Comp. Med. 35:121-160.

Davey MW, James CE, Hudson AL (2009). Drug resistance mechanisms in helminths: is it survival of the fittest? Trends Parasitol. 25(7):328-335.

Dawson JM, Buttery PJ, Jenkins D, Wood CD, Gill M (1999). Effects of dietary Quebracho tannin on nutrient utilization and tissue metabolism in sheep and rats. J. Sci. Food Agric. 79:1423-1430.

Dharani N, Rukunga G, Yenessew A, Mbora A, Mwaura L, Dawson I, Jamnadass $R$ (2010). Common antimalarial trees and shrubs of East Africa: a description of species and guide to cultivation and conservation through use. World Agroforestry Centre (ICRAF), Nairobi, Kenya. ISBN: 978-92-9059-238-9.

Donahue MJ, Yacoub NJ, Kaeini MR, Masaracchia RA, Harris BG (1981). Glycogen metabolizing enzymes during starvation and feeding of $A$. suum maintained in a perfusion. J. Parasitol. 67(4):505510.

Forbey JS, Harvey AL, Huffman MA, Provenza FD, Sullivan R, Tasdemir D (2009). Exploitation of secondary metabolites by animals: A response to homeostatic challenges. Integr. Comp. Biol. 49(3):314328.

Francis G, Kerem Z, Makkar HPS, Becker K (2002). The biological action of saponins in animal systems: a review. Brit. J. Nutr. 88:587-605.

Gakuya DW (2001). Pharmacological and clinical evaluation of the anthelmintic activity of Albizia anthelmintica Brogn, Maerua edulis De wolf and Maerua subcordata De wolf plant extracts in sheep and mice. PhD Thesis, University of Nairobi, Kenya.

Gill JH, Redwin JM, van Wyk JA, Lacey E (1991). Detection of resistance to ivermectin in Haemonchus contortus. Int. J. Parasitol. 21:771-776.

Githiori JB, Athanasiadou S, Thamsborg SM (2006). Use of plants in novel approaches for control of gastrointestinal helminths in livestock with emphasis on small ruminants. Vet. Parasitol.139:308-320.

Harborne JB (1973). Phytochemical Methods. Chapman and Hall, London p. 113.

Harborne JB (1998). Phytochemical Methods. A guide to modern techniques of plant analysis, $3^{\text {rd }}$ Edn. , Chapman and Hall, London, $p$. 235.

Hedberg I, Hedbrerg O, Madati PJ, Mshigeni KE, Mshiu EN, Samuelsson G (1983b). Inventory of plants used in traditional medicine in Tanzania. Part III. Plants of the families PapilionaceaeVitaceae. J. Ethnopharmacol. 9:237-260.

Hoste $H$, Jackson F, Athanasiadou S, Thamsborg SM, Hoskin SO (2006). The effects of tannin-rich plants on parasitic nematodes in ruminants. Trends Parasitol. 22(6):253-261.

Ian SC, Khan TE, Curran MM, McCorkle MC (2007). Ethnoveterinary Medicine: Potential solutions for large scale problems? In: Wynn S.G, and Fougere $(\mathrm{Ed})$. Veterinary Herbal medicine. Library of Congress cataloging-in publication data. ISBN: 10:0-323-02998-1. p. 695

Johns T, Kokwaro JO, Kimanani EK (1990). Herbal remedies of the Luo of Siaya district, Kenya: establishing quantitative criteria for consensus. Econ. Bot. 44:369-381.

Kaplan RM, Klei TR, Lyons ET, Lester G, Courtney CH, French DD, Tolliver SC, Vidyashankar AN, Zhao Y (2004). Prevalence of anthelmintic resistant cyathostomes on horse farms. J. Am. Vet. Med. Assoc. 225:903-910.

Katende AB, Birnie A, Tengnas B (1995). Useful Trees and shrubs for Uganda. Identification, propagation and management for Agricultural and livestock communities. Technical Handbook No. 10. Regional Soil Conservation Unit, RSCU, 1995

Kato A, Moriyasu H, Ichimaru H, Nishiyama Y, Yuma FD, Nganga JN, Mathenge SG, Ogeto JO (1996). Isolation of alkaloidal constituents of Zanthoxylum umbarence and Zanthoxylum chalybeum using ion-pair HPLC. J. Nat. Prod. 59:316-318.

Kaufman PB, Cseke LJ, Warber S, Duke JA, Brielmann HL (1999). Natural Products from Plants. CRC Press, Boca Raton, FL

Kotze AC, Clifford S, O'Grady J, Behnke JM, McCarthy JS (2004). An in vitro larval motility assay to determine anthelmintic sensitivity for human hookworm and strongyloides species. Am. J. Trop. Med. Hyg. 71(5):608-616.

Lamson PD, Brown HW (1936). Methods of testing the anthelmintics 
properties of asacriciedes. Am. J. Hyg. 23:85-103.

Lullman HK, Morh, Bieger D (1993). Colour Atlas of pharmacology, Theme medical publisher, Inc. New York, pp. 52-98.

Makut MD, Gyar SD, Pennap GRI, Anthony D (2008). Phytochemical screening and antimicrobial activity of ethanolic and methanolic extracts of leaf and bark of Khaya senegalensis. Afr. J. Biotechnol. 7(99):1216-1219.

Malu SP, Obochi GO, Edem CA, Nyong BE (2009). Effect of methods of extraction on phytochemical constituents and antibacterial properties of Tetracarpidium conophorum seeds. Global J. Pure Appl. Sci. 15(3):373-376.

Marie-Magdeleine C, Hoste H, Mahieu M, Varo H, Archimede H (2009). In vitro effects of Cucurbita moschata seed extracts on Haemonchus contortus. Vet. Parasitol. 161:99-105.

Martin RJ (1997). Modes of action of anthelmintic drugs. Vet. J. 154(1):11-34.

Melaku A, Bogale B, Chanie M, Fentahun T, Berhanu A (2013). Study on utilization and efficacy of commonly used anthelmintics against gastrointestinal nematodes in naturally infected sheep in North Gondar, North-Western Ethiopia. Afr. J. Pharm. Pharmacol. Vol. 7(12):679-684.

Min BR, Barry TN, Attwood GT, McNabb WC (2003). The effect of condensed tannins on the nutrition and health of ruminants fed fresh temperate forages: a review. Anim. Fed. Sci. Tech. 106:3-19.

Nalule AS, Mbaria JM, Olila D, Kimenju JW (2011). Ethnopharmacological practices in management of livestock helminthes by pastoral communities in the drylands of Uganda; Livestock Res. Rural Dev. 23(2):11

Nguta JM, Mbaria JM, Gakuya DW, Gathumbi PK, Kiama SG (2010). Antimalarial herbal remedies of Msambweni, Kenya. J. Ethnopharmacol. 128(2):424-432.

Olila D, Olwa-Odyek, Opuda-Asibo J (2002). Screening extracts of Zanthoxylum chalybeum and Warburgia ugandensis for activity against measles virus (Swartz and Edmonston strains) in vitro. Afr. J. Health Sci. 2(1):2-10.

Olila D, Opuda-Asibo J, Odyek-Olwa (2001b). Antibacterial and antifungal activities of extracts of Zanthoxylum chalybeum and Warburgia ugandensis, Ugandan medicinal plants. Afr. J. Health Sci. 1:66-72.

Olila D, Opuda-Asibo J, Odyek-Olwa (2001a). Bioassay-guided studies on the cytotoxic and in vitro trypanocidal activities of a sesquiterpene (Muzigadial) derived from a Ugandan medicinal plant (Warburgi ugandensis). Afr. J. Health Sci. 1:12-15.

Paolini V, Fouraste I, Hoste H (2004). In vitro effect of three woody plants and sainfoin extracts on $3^{\text {rd }}$-stage larvae and adult worms of three gastrointestinal nematodes. Parasitol.129(01):69 -77.

Rujjanawate C, Kanjanapothi D, Panthong A (2003). Pharmacological effect and toxicity of alkaloids from Gelsemium elegans Benth. J. Ethnopharmacol. 89(1):91-95.

Runyoro DKB, Ngassapa OD, Matee MIN, Joseph CC, Moshi MJ (2006). Medicinal plants used by Tanzanian traditional healers in the management of Candida infections. J. Ethnopharmacol. 106:158165.

Sargison ND, Jackson F, Bartley DJ, Wilson DJ, Stenhouse LJ, Penny CD (2007). Observations on the emergence of multiple anthelmintic resistance in sheep flocks in the south-east of Scotland. Vet. Parasitol. 145:65-76.

Satou T, Koga M, Matsuhashi R, Koike K, Tada I, Nikaido T (2002). Assay of nematocidal activity of isoquinoline alkaloids using third stage larvae of Strongyloides ratti and $S$. venezuelensis. Vet. Parasitol. 104:131-138.

Schoenian S (2008). Understanding anthelmintics (dewormers). Small Ruminant Info Series. Western Maryland Research \& Education Center, University of Maryland Cooperative Extension. Available at: ttp://www.sheepandgoat.com/articles/anthelminticswork.html.
Stangeland T, Wangensteen H, Katuura E, Lye KA, Paulsen BS (2010). Antioxidant and anti-plasmodial activity of extracts from three Ugandan medicinal plants. J. Med. Plants Res. 4(18):1916-1923.

Taniguchi M, Chapya A, Kubo I, Nakanishi K (1978). Screening of East African plants for antimalarial activity. Chem. Pharm. Bull. 26:29102913.

Tarnopolsky MA, Beal MF (2001). Potential for creatine and other therapies targeting cellular energy dysfunction in neurological disorders. Ann. Neurol. 49:561-574.

Tchamadeu MC, Dzeufiet PDD, Kouambou NCC, Azebaze AGB, Allard J, Girolami JP, Tack, I, Kamtchouing P, Dimo T (2010). Hypoglycaemic effects of Mammea africana (Guttiferae) in diabetic rats. J. Ethnopharmacol. 127:368-372.

Tinsley RC, York JE, Everard ALE, Stott LC, Chapple SJ, Tinsley MC (2011). Environmental constraints influencing survival of an African parasite in a north temperate habitat: effects of temperature on egg development. Parasitology 1-10.

Tran G (2011). Knob wood (Zanthoxylum chalybeum). Feedipedia.org. A programme by INRA, CIRAD, AFZ and FAO. Accessed from http://www.feedipedia.org/node/156

Waghorn GC, McNabb WC (2003). Consequences of plant phenolic compounds for productivity and health of ruminants. Proceedings of the Nutrition Society 62:383-392.

Wagner G, Blatt S (1996). Plant drug analysis, a thin layer chromatography, atlas, $2^{\text {nd }}$ Ed, CS Pringer Verlag, pp. 352-355.

Wasswa P, Olila D (2006). The in vitro Ascaricidal activity of selected indigenous medicinal plants used in ethno- veterinary practices in Uganda. Afr. J. Tradit. Complement Altern. Med. 3:94-103.

Waterman C, Smith RA, Pontiggia L, DerMarderosian A (2010). Anthelmintic screening of Sub-Saharan African plants used in traditional medicine. J. Ethnopharmacol. 127(3):755-759.

Waterman PG (1992). Role for secondary metabolites in plants. Ciba Foundation symposia 171:255-275.

Weaver HJ, Hawdon JM, Hoberg EP (2010). Soil-transmitted helminthiases: implications of climate change and human behavior. Review Article. Trends Parasitol. 26(12):574-581.

Wolstenholme AJ, Fairweather I, Prichard R, von SamsonHimmelstjerna G, Sangster N (2004). Drug Resistance in Veterinary Helminthes. Trends Parasitol. 20:469-476.

Wynn SG, Fougere BJ (2007). Introduction: Why use herbal medicine. In: Wynn SG, Fougere BJ (Eds). Veterinary Herbal medicine. Library of Congress cataloging-in publication data. p695. ISBN: 10:0-32302998-1. 